\title{
Plasma Exchange as A Therapeutic Alternative to Eliminate Viral RNA and Macromolecules Involved in The Immune Response of Patients with Sars-Cov-2
}

\author{
Torres Estrella Carlos Uriel ${ }^{1,2 \#, ~ M o ́ n i c a ~ S i e r r a ~ M a r t i ́ n e z ~}{ }^{3 \#, ~ M i g u e l ~ A ́ n g e l ~ C h a ́ v e z ~ M a r t i ́ n e z ~}{ }^{4}$, \\ Eduardo García Salazar ${ }^{1,5}$ and Gustavo Acosta Altamirano ${ }^{1,5 *}$ \\ ${ }^{1}$ Molecular Diagnosis Laboratory, High Specialty Regional Hospital of Ixtapaluca, Mexico
}

${ }^{2}$ Interdisciplinary Professional Biotechnology Unit, National Polytechnic Institute, Mexico

${ }^{3}$ Research unit, Juárez Hospital of Mexico, Mexico

${ }^{4}$ Blood Bank, Regional Hospital of High Specialty of Ixtapaluca, Mexico

${ }^{5}$ Superior School of Medicine, National Polytechnic Institute, Mexico

${ }^{\#}$ Both authors contributed equally to this work

*Corresponding author: Gustavo Acosta Altamirano, Molecular Diagnosis Laboratory, High Specialty Regional Hospital of Ixtapaluca, Superior School of Medicine, National Polytechnic Institute, Mexico

\section{ARTICLE INFO}

Received: 幽 July 13, 2020

Published: 㗀 July 22, 2020

Citation: Torres Estrella CU, Sierra M, Chàvez Martínez MA, García-Salazar E, Acosta G. Plasma Exchange as A Therapeutic Alternative to Eliminate Viral RNA and Macromolecules Involved in The Immune Response of Patients with Sars-Cov-2. Biomed J Sci \& Tech Res 29(1)-2020. BJSTR. MS.ID.004742.
ABSTRACT

Viral sepsis represents a great problem for the COVID-19 patient as it causes several immunologic and hematologic disorders that lead to an early death. For this reason, we considered implementing the plasma exchange treatment in a patient who previously tested positive for COVID-19 in a nasal and oropharyngeal swab sample. Afterward, the molecular diagnosis was performed in hematic components, and the virus was detected in plasma. The treatment was conducted in the blood bank of the Hospital High Specialty Regional of Ixtapaluca, extracting $2073 \mathrm{~mL}$ of plasma and compensating with $1600 \mathrm{~mL}$ of isotonic saline solution and $400 \mathrm{~mL}$ of albumin $(12.5 \mathrm{~g} / 50 \mathrm{ml})$. After the treatment, the patient showed a notable recovery and a decreased viral charge in the molecular detection of the virus after the plasma exchange. These results suggest the possibility of making the diagnosis in blood plasma and implementing hematologic treatments in patients infected with SARS-CoV-2.

Keywords: COVID-19; SARS-CoV-2; Viral sepsis; Plasma exchange; qRT-PCR

\section{Short Communication}

From the beginning of the SARS-CoV-2 outbreak in Wuhan, China, in December 2019, the rapid propagation on a worldwide scale has severely impacted the health systems [1]. According to the official reports in Mexico, 226,089 cumulative positive cases and 27,786 deaths approximately have been reported due to COVID-19 [2]. The acute inflammation, whose pathology derives from a high IL-6 concentration, is directly related to the phenomenon known as "cytokine storm," in which a cascade of excessive signaling of the proinflammatory immune response occurs along with other cytokines (IL-10 and TNF- $\alpha$ ). These currently seem to be responsible for the reduction and exhaustion of $\mathrm{T}$ cells due to viral sepsis, as well as a high macrophage activity, which is still being studied $[3,4]$. Diverse mechanisms of the physiopathology caused by this new coronavirus have been proposed; however, a recent study indicates that the SARS-CoV-2 possibly affects the $1-\beta$ chain of hemoglobin, thus capturing porphyrin and the inhibiting the metabolism of the heme [5] group. The previous would reaffirm the occurrence of viral sepsis in patients that acquire the disease, although more studies 
must be conducted to prove this hypothesis. Being able to detect the SARS-CoV-2 in hematic components represent an opportunity to identify what is involved in the "transportation" of the virus through the bloodstream; managing thus to develop and implement treatments that allow the reduction of viral infection levels.

The therapeutic plasma exchange is used in systemic autoimmune diseases; its principle is based on eliminating antibodies and preformed immunocomplexes to avoid tissue damage, as well as mediating the inflammation (cytokines) [6]. For this reason, the objective of this work was to implement the plasma exchange treatment to decrease the circulating viral RNA and macromolecules involved in the inflammatory response, hence avoiding the development of clinical complications.

\section{Materials and Methods}

A 44-year-old patient with no comorbidities of hypertension, obesity, or diabetes; with fever, cephalea, and dyspnea symptoms and oxygen saturation (SPO2) of 84\% was diagnosed as COVID-19 positive in a nasal and oropharyngeal swab sample. The nucleic acid extraction was performed with the QIAamp Viral RNA Mini kit (Qiagen, GE) following the manufacturer's instructions. The detection of SARS-CoV-2 was accomplished through the Real-Time Reverse Transcription Polymerase Chain Reaction (qRT-PCR) using the commercial kit RealStar@ SARS-CoV-2 RT-PCR Kit 1.0 (Altona Diagnostics, GE), showing a Ct (Cycle threshold) of 13.29 for the S gene (Figure 1a). Because of the early $\mathrm{Ct}$, the patient was considered for molecular diagnosis in hematic components (red blood cells, lymphocytes, platelet concentrate, and plasma), managing to detect the virus only in the plasma sample with a $\mathrm{Ct}$ of 36.87 (Figure 1b). After the virus detection in plasma, the patient underwent a threehour plasma exchange procedure (with prior informed consent), which was conducted in the hospital's blood bank in an apheresis machine (TERUMO BCT Spectra Optia Apheresis System). A total of $2073 \mathrm{~mL}$ of plasma were extracted and were compensated with $1600 \mathrm{~mL}$ of isotonic saline solution and eight albumin vials $(12.5$ $\mathrm{g} / 50 \mathrm{~mL}$ ) for a final volume of $2000 \mathrm{ml}$. After the procedure ended, the patient was transferred to his residence with paracetamol every 8 hours for ten days as treatment.
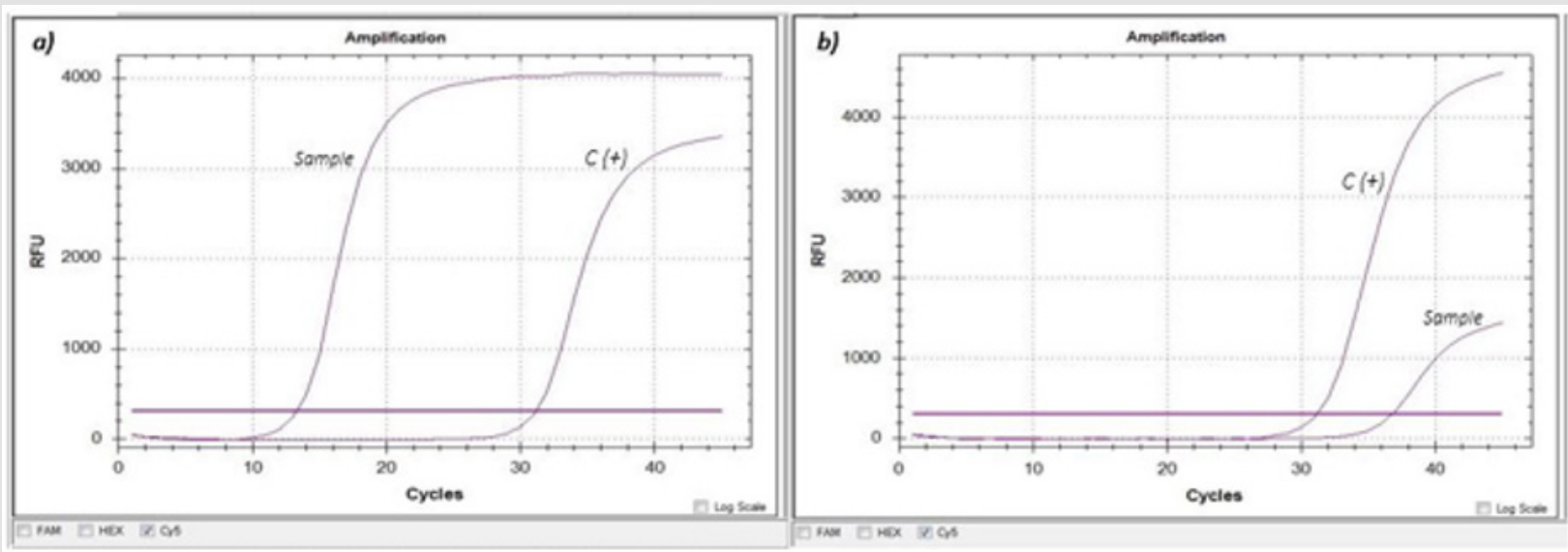

Figure 1: Molecular detection of SARS-CoV-2 through qRT-PCR (RealStar SARS-CoV-2 RT-PCR Kit 1.0, Altona Diagnostics).

a) Nasal and oropharyngeal swab sample, where an early amplification $(\mathrm{Ct}=13.29)$ of the $\mathrm{S}$ gene (SARS-CoV-2 labeled with Cy5) is observed against the positive control $(\mathrm{C}+)$.

b) Plasma sample, where the amplification $(\mathrm{Ct}=36.87)$ of the $\mathrm{S}$ gene, is observed.

\section{Results}

In the days following the plasma exchange, the patient presented decreased fever and general discomfort with an SPO2 of 90\%. Seven days after the plasma exchange treatment, the molecular detection for SARS-CoV-2 was conducted again in a nasal and oropharyngeal sample and plasma sample, observing a positive result in both samples for the amplification of the $\mathrm{S}$ gene, with a $\mathrm{Ct}=32.5$ value in the nasal and oropharyngeal sample (Figure $2 \mathrm{a}$ ) and a $\mathrm{Ct}=39.01$ in plasma (Figure 2b). An increase in the $\mathrm{Ct}$ was observed in both samples compared to the values found during diagnosis. 


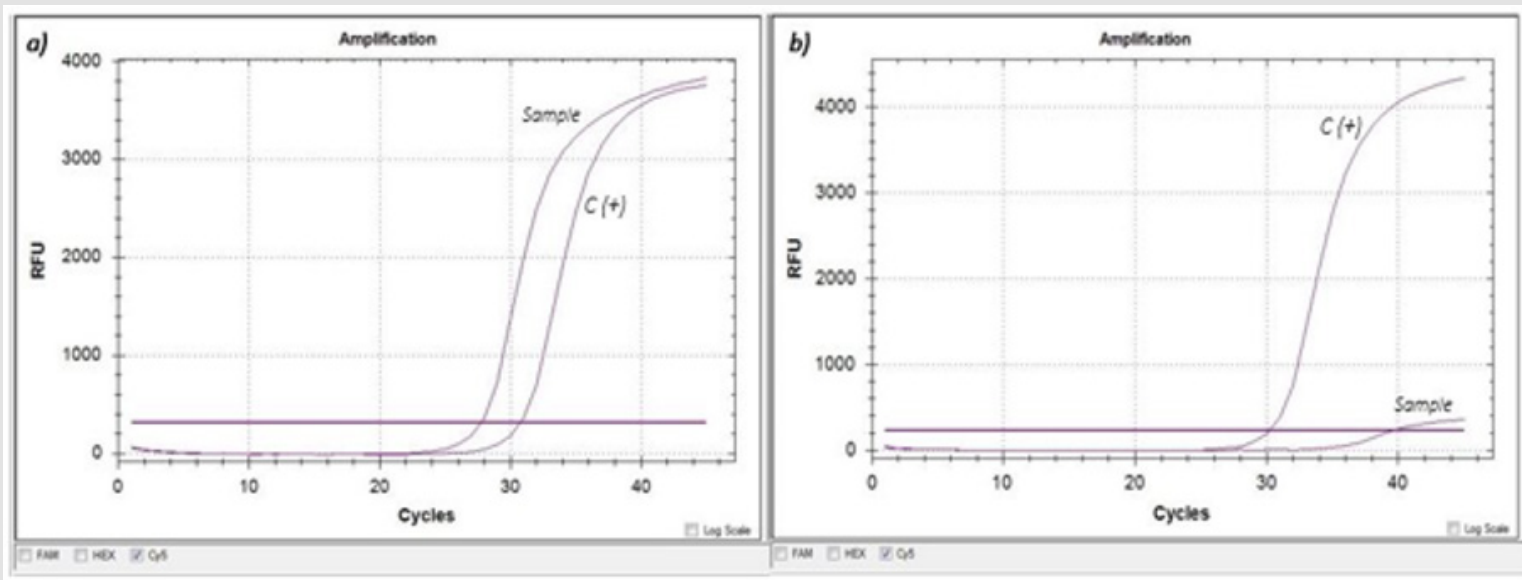

Figure 2: Molecular detection of SARS-CoV-2, through qRT-PCR (RealStar SARS-CoV-2 RT-PCR Kit 1.0, Altona Diagnostics), seven days after the plasma exchange treatment.

a) Nasal and oropharyngeal swab sample, where an amplification $(\mathrm{CT}=32.5)$ of the $\mathrm{S}$ gene $(\mathrm{SARS}-\mathrm{CoV}-2$ labeled with $\mathrm{Cy} 5)$ is observed against the positive control.

b) Plasma sample where amplification of the $\mathrm{S}$ gene $(\mathrm{Ct}=39.01)$ is observed.

\section{Discussion}

The plasma exchange is not a new treatment, it has been applied in patients with autoimmune diseases, and recently, in COVID-19 grave patients in several countries [6]. However, its benefit remains controversial as some researches report that the plasma exchange in convalescent patients is safe, while others claim that it is not an entirely safe procedure [7]. In the present work, two important aspects were demonstrated: 1) the SARSCoV-2 virus can be detected in plasma when the amplification in nasal and oropharyngeal samples appears since the $10^{\text {th }}$ cycle, and 2) the plasma exchange reduced the presence of circulating viral RNA which was reflected in the patient's symptomatology. The plasma exchange did not cause adverse effects on the patient, who currently remains asymptomatic and afebrile with no complications attributable to the procedure. The previous observation contrast against the reports made by Honore et al. [8], who claim that plasma exchange in convalescent patients is not safe. Therefore, it is necessary to conduct more studies to demonstrate the utility of plasma exchange in COVID-19 patients.

\section{Conclusion}

The SARS-CoV-2 detection in plasma represents an opportunity to identify patients who are candidates for hematologic treatments. The plasma exchange might be an alternative therapeutic strategy to reduce the viral charge and avoid sepsis and severe complications that lead to an early death.

\section{Acknowledgment}

The authors thank Dr. Carlos Vargas for his support in the plasma exchange procedure, Dr. María Guadalupe Frías De León for her support in the preparation of this manuscript, and Ladislao Amador for the technical support.

\section{References}

1. Patrucco F, Gavelli F, Shi R, De Vita N, Pavot A, et al. (2020) Coronavirus disease 2019 outbreak. Panminerva Med 66(2): 73-74.

2. Secretaría de Salud (2020) COVID-19 Mexico National General Report, Mexico.

3. Merad M, Martin IC (2020) Pathological inflammation in patients with COVID-19: a key role for monocytes and macrophages. Nat Rev Immunol 20(6): 355-362.

4. Diao B, Wang C, Tan Y, Chen X, Liu Y, et al. (2020) Reduction and Functional Exhaustion of T Cells in Patients With Coronavirus Disease 2019 (COVID-19). Front Immunol. 1: 1-7.

5. Liu W, Li H (2020) COVID-19: Attacks the 1-Beta Chain of Hemoglobin and Captures the Porphyrin to Inhibit Human Heme Metabolism. ChemRxiv.

6. Keith P, Day M, Perkins L, Moyer L, Hewitt K, et al. (2020) A novel treatment approach to the novel coronavirus : an argument for the use of therapeutic plasma exchange for fulminant. Crit Care 24(128): 1-3.

7. Lerzan Dogan, Dilaver Kaya, Tugce Sariykaya, Rehile Zengin, Alp Dincer, et al. (2020) Plasmapheresis treatment in COVID-19 - related autoimmune meningoencephalitis: Case series. Brain, Behavior and Immunity Elsevier 87: 155-158

8. Honore PM, Mugisha A, Kugener L, Kugener L, Redant S, et al. (2020) Therapeutic plasma exchange as a routine therapy in septic shock and as an experimental treatment for COVID-19: we are not sure. Crit Care 24 (128): 4-5. 
ISSN: 2574-1241

DOI: $10.26717 /$ BJSTR.2020.29.004743

Gustavo Acosta Altamirano. Biomed J Sci \& Tech Res

(c) (P) This work is licensed under Creative

Submission Link: https://biomedres.us/submit-manuscript.php

$\begin{array}{ll}\text { BIOMEDICAL } & \text { Assets of Publishing with us } \\ \text { RESEARCHES } & \text { - Global archiving of articles } \\ \text { - Immediate, unrestricted online access }\end{array}$

